Article

\title{
Assessing the Standard of Health and Welfare in Individual Categories of Cattle from the Viewpoint of Intravital Pathological Changes
}

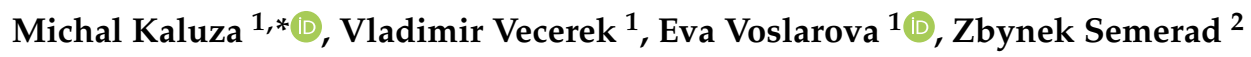 \\ and Annamaria Passantino ${ }^{3}$ (D) \\ 1 Department of Animal Protection and Welfare and Veterinary Public Health, Faculty of Veterinary Hygiene \\ and Ecology, University of Veterinary and Pharmaceutical Sciences Brno, 61242 Brno, Czech Republic; \\ vecerekv@vfu.cz (V.V.); voslarovae@vfu.cz (E.V.) \\ 2 Central Veterinary Administration of the State Veterinary Administration, 12000 Prague, Czech Republic; \\ z.semerad@svscr.cz \\ 3 Department of Veterinary Sciences, University of Messina, Polo Universitario Annunziata, \\ 98168 Messina, Italy; passanna@unime.it \\ * Correspondence: kaluzam@vfu.cz
}

Received: 19 September 2020; Accepted: 8 December 2020; Published: 10 December 2020

\begin{abstract}
The standard of the health and welfare of individual categories of cattle was assessed from the viewpoint of intravital pathological changes. The results of veterinary inspections of 2,514,666 head of cattle (1,136,754 cows, 257,912 heifers, 1,015,541 bulls and 104,459 calves) slaughtered in the Czech Republic in the period from 2010 to 2019 were analyzed. The results show significant differences $(p<0.01)$ between the categories of cattle in the total numbers of intravital findings. Intravital findings were most frequently recorded in cows (index 2.271) and least frequently recorded in bulls (index 0.479). In all categories of cattle, chronic findings predominated, where the largest number was recorded in cows (index 1.740) and calves (index 0.910). Parasitic and traumatic findings were only detected in low numbers in all categories of cattle. Assessment of the trend in the total number of intravital pathological findings in individual categories of cattle in the monitored period showed an evident fall in heifers ( $\mathrm{rSp}=-0.915, p<0.01)$, cows ( $\mathrm{rSp}=-0.806, p<0.01)$ and bulls $(\mathrm{rSp}=-0.636, p<0.05)$. In calves, no decreasing trend was found ( $\mathrm{rSp}=-0.382, p>0.05)$. The results obtained in this study do not merely reflect the standard of health of the animals slaughtered at abattoirs in the Czech Republic, but also provide a picture of the standard of the living conditions provided by farmers rearing individual categories of cattle.
\end{abstract}

Keywords: slaughterhouse; veterinary inspection; intravital findings; health; welfare

\section{Introduction}

Veterinary inspections at abattoirs are not merely a critical element for controlling the quality and safety of animal products, but are also an appropriate source of data for monitoring a wide range of diseases and conditions relating to the health and living conditions of animals [1]. The occurrence of disease and the individual's state of health itself are also important factors influencing animal welfare [2]. Evaluating findings at abattoirs can also be employed to adjudge the standard of the slaughtered animals' living conditions [3]. Regular analysis of the causes of the partial or complete seizures of carcasses also provides an opportunity both for determining the character and prevalence of lesions on animal carcasses and for monitoring trends in the occurrence of diseases over the course of time [4]. Similarly, Fries [5] considered the results of inspections on slaughtered animals and meat at abattoirs to be an important indicator of the health of food animals at the level of individual abattoirs 
and farms. The findings made during veterinary inspections may also stimulate farmers to improve living conditions for their animals, which may subsequently be reflected in the health, condition and, of course, quality of the animal products from these animals.

The standard of welfare is a fundamental topic today in relation to both pets and livestock husbandry. The requirements for good living conditions may differ between individuals depending on their physical and mental state [6]. Welfare in intensive farming generally comes up against the interests of farm management and its economics. Troeger [7] emphasized the fact that animal welfare must be assured not just on farms, but also during transportation and the stunning and bleeding of animals at abattoirs. Transport is an important event for animals that may affect their welfare. Simova et al. [8], however, also emphasized the fact that the welfare of transported animals need not be affected if stress factors can be adequately eliminated before transport itself.

The results of veterinary inspection are also an appropriate tool in preventive medicine for cattle. Nicholson et al. [9] found a higher frequency of the studied range of findings in dairy cows ( $37 \%$ of animals) than in beef cows ( $28 \%$ of animals). A comparison between beef bulls and dairy bulls revealed that pathological changes were more frequent in beef bulls, $(23.9 \%)$ than in dairy bulls $(19.7 \%)$. The results of other published studies point to the fact that pathological findings occur in a large number of the organs of animal carcasses [10,11]. Dupuy et al. [12] studied the occurrence of findings at ten abattoirs in France in the period of 2005-2010. Of the total number of 1,937,917 head of cattle, 381,186 showed findings that provided a reason for seizure. The number of animals with at least one reason for partial seizure ranged between $10 \%$ and $36 \%$. Kozak et al. [13] came to the conclusion, on the basis of the results of their study into the edibility of carcasses at abattoirs in the Czech Republic in the years 1989-2000, that the health of slaughtered animals improved markedly in bulls and heifers in the monitored period. No improvement to the health of cows or calves was recorded. Vecerek et al. [14], in contrast, discovered an overall increase in the number of cattle carcasses condemned at abattoirs in the Czech Republic between 1995 and 2002. Lis [11,15,16] studied the occurrence of pathological lesions in cattle in Poland. A total of 1,707,720 head of adult cattle and 192,373 calves were slaughtered in 1994. During inspection before and after slaughter, pathological lesions were found on $21.9 \%$ of animals [16]. The authors recorded a fall in the number of pathological lesions in comparison with 1987 , when such findings were made on $43.9 \%$ of adult cattle and $42.7 \%$ of calves. In 2000 , pathological findings were detected in $25.1 \%$ of adult cattle and $3.8 \%$ of calves [15]. The results for 2003 show a slight increase in the occurrence of pathological findings, which were confirmed in $28.1 \%$ of adult cattle and $5.4 \%$ of calves [11].

In regard to the origin of pathological findings, the literature primarily describes the occurrence of parasitic findings. The parasitic findings most frequently detected in cattle at abattoirs are cysticercosis and liver and rumen fascioliasis $[17,18]$. There are, however, differences in the prevalence of parasites in various countries. Cassini et al. [19] and Mage et al. [20] found the prevalence of cysticercosis and trematodes to differ markedly in the individual EU member states. Dupuy et al. [21,22] mentioned the fact that tapeworms tend to be a rare finding at abattoirs at the present time in most of the countries of Western Europe. Differences in the occurrence of parasitic findings may, in any case, be the result of the varying sensitivity of veterinary inspections in individual states, as has been noted by Cabaret et al. [23].

The aim of this study was to assess the state of health and welfare of cattle by means of the determination of the number of intravital pathological changes found during veterinary inspections performed at abattoirs on cattle slaughtered in the Czech Republic in the period from 2010 to 2019. It also aimed to evaluate whether there are differences between individual categories of cattle in the overall frequency of findings and according to the character of damage, and to determine the trend in the number of intravital pathological changes. 


\section{Materials and Methods}

\subsection{Data Collection}

Data archived in the information system of the State Veterinary Administration of the Czech Republic were used for the assessment of the standard of health and welfare of slaughtered cattle. Data on the number of slaughtered animals and the results of the veterinary inspections recorded by official veterinary inspectors at all abattoirs in the Czech Republic are stored in this system. The subject of evaluation in this study was the results of veterinary inspections on cattle slaughtered at abattoirs in the Czech Republic in the period from 2010 to 2019. The dataset consisted of 1,136,754 cows, 257,912 heifers, 1,015,541 bulls and 104,459 calves, i.e., all cattle slaughtered in slaughterhouses in the Czech Republic in the monitored period. The individual categories of cattle were determined as follows: calves (up to 6 months of age), heifers (females from 6 months to first calving), cows (females after first calving) and bulls (males above 6 months of age).

For the purposes of the study, the total numbers of intravital pathological changes in individual categories of cattle slaughtered at abattoirs (cows, heifers, bulls, calves) were evaluated separately. Indices of the ratio of the number of intravital pathological findings to the number of slaughtered animals were calculated from the data obtained. Subsequently, the indices for the individual categories of cattle were compared.

\subsection{Classification of Pathological Changes}

Individual intravital pathological findings in cows, heifers, bulls and calves were divided into acute, chronic, traumatic, parasitic and other findings. The occurrence of findings according to the character of damage was studied in each cattle category and further compared between cattle categories.

Pathological changes associated with short-term inflammatory processes in the organism were classified among acute findings. These are, first and foremost, findings on individual organs including pronounced hyperaemia, the presence of haemorrhages, swelling, increased organ size, the presence of catarrhal, haemorrhagic, purulent or fibrinous exudates, etc.

Pathological changes associated with prolonged inflammatory processes and functional or morphological changes in tissues and organs were classed as chronic findings. These are, first and foremost, findings on individual organs including changes to the original structure of tissue parenchyma involving penetration of connective tissue, the formation of connective tissue scarring and the appearance of adhesions. The chronic findings are also indicated by a reduction in the size of organs and their stiffness, a change to the structure of the surface of mucous membranes and serous membranes associated with their becoming rough, the presence of post-inflammatory cavities, the presence of cysts or abscesses displaying calcification, etc.

Findings of trauma point to the standard of welfare of the slaughtered animals. They may be the result of the action of agents immediately before slaughter (acute) or at a far earlier time (chronic), for which reason these were classified separately. Changes including open wounds at various stages of healing, haematoma in the hypodermis and muscle, contusions, dislocations, fractures (open and closed fractures) and changes to internal organs (haemorrhages and ruptures) resulting from inappropriate handling, direct damage resulting from the use of means of technology, as a result of transport or resulting from fighting between animals were classed as traumatic findings. Post-mortem changes resulting from stunning were not included.

Changes that point to the invasion and migration of parasites and pathological processes caused by parasites in the organism of the host were classed as parasitic findings. This was assessed primarily by the presence of cysticerci at predilection sites-the heart, the esophagus, the diaphragm, the sublingual area and the masticatory muscles. In addition to cysticercosis, we also assessed parasitic findings on the lungs-nematodes-and the occurrence of sarcocystis.

Other changes that could not, in view of the origin of the findings, be classed in the above categories were classed as other findings. This category therefore includes non-inflammatory changes 
and tumours on the skin, icterus, pathological pregnancy, genital developmental defects and total and/or organ intravital findings that could not be assigned to any other group of findings.

\subsection{Statistical Analysis}

The results were evaluated statistically using the program Unistat 6.5 for Excel. For the purposes of statistical comparison of the frequency of findings in individual categories, a chi-square test was used to assess statistical significance in a $2 \times 2$ contingency table. Yates' correction was used on frequencies exceeding 5, while Fisher's exact test was used at frequencies lower than 5. Spearman's rank test was used to assess the trend in the number of intravital pathological findings. The result of testing was the determination of Spearman's rank correlation coefficients (rSp) used to assess a positive or negative trend in the numbers of findings. A value of $p<0.05$ was considered statistically significant.

\section{Results}

A total of 2,514,666 head of cattle (1,136,754 cows, 257,912 heifers, 1,015,541 bulls and 104,459 calves) were slaughtered at abattoirs in the Czech Republic in the period from 2010 to 2019. The total number of intravital pathological changes in cows, heifers, bulls and calves found during veterinary inspection at abattoirs is given in Table 1. The results show that cows were the category of cattle with the most frequently recorded intravital findings. The index of the ratio of the number of intravital findings to the number of cows slaughtered was 2.271. The lowest number of intravital findings was detected in bulls (index 0.479). The differences in the indices between all the categories of cattle were statistically highly significant $(p<0.01)$.

Table 1. Comparison of the total number of intravital pathological (PA) changes in individual categories of cattle.

\begin{tabular}{ccccc}
\hline Category & Cows & Heifers & Bulls & Calves \\
\hline slaughtered animals $(n)$ & $1,136,754$ & 257,912 & $1,015,541$ & 104,459 \\
intravital PA findings $(x)$ & $2,581,486$ & 206,281 & 486,916 & 168,998 \\
IR $=x / n$ & $2.271^{\text {a }}$ & $0.800^{\mathrm{c}}$ & $0.479^{\mathrm{d}}$ & $1.618^{\mathrm{b}}$ \\
\hline
\end{tabular}

$n=$ number of slaughtered animals; $x=$ total number of intravital PA findings; IR = index of ratio of number of intravital PA findings to number of slaughtered animals; $a-d$ values within a row with different superscripts differ significantly $(p<0.01)$.

The occurrence of pathological findings according to the character of damage in individual categories of cattle is given in Table 2.

Table 2. Comparison of the number of pathological findings according to the character of damage in individual categories of cattle.

\begin{tabular}{|c|c|c|c|c|c|c|c|c|}
\hline \multirow[b]{3}{*}{ Findings } & \multicolumn{8}{|c|}{ Category } \\
\hline & \multicolumn{2}{|c|}{$\begin{array}{c}\text { Cows } \\
(n=1,136,754)\end{array}$} & \multicolumn{2}{|c|}{$\begin{array}{c}\text { Heifers } \\
(n=257,912)\end{array}$} & \multicolumn{2}{|c|}{$\begin{array}{c}\text { Bulls } \\
(n=1,015,541)\end{array}$} & \multicolumn{2}{|c|}{$\begin{array}{c}\text { Calves } \\
(n=104,459)\end{array}$} \\
\hline & number & $\%$ & number & $\%$ & number & $\%$ & number & $\%$ \\
\hline acute & 340,207 & $29.93^{b, w}$ & 21,842 & $8.47^{\mathrm{c}, \mathrm{w}}$ & 37,768 & $3.72^{d, w}$ & 31,960 & $30.60^{a, x}$ \\
\hline chronic & $1,976,472$ & $173.87^{\mathrm{a}, \mathrm{v}}$ & 157,659 & $61.13^{c, v}$ & 414,343 & $40.80^{\mathrm{d}, \mathrm{v}}$ & 95,277 & $91.21^{b, v}$ \\
\hline traumatic & 19,484 & $1.71^{a, y}$ & 1853 & $0.72^{b, z}$ & 2865 & $0.28^{\mathrm{d}, \mathrm{z}}$ & 474 & $0.45^{c, y}$ \\
\hline parasitic & 15,853 & $1.40^{\mathrm{b}, \mathrm{z}}$ & 5301 & $2.06^{a, y}$ & 9059 & $0.89^{c, y}$ & 239 & $0.23^{\mathrm{d}, \mathrm{z}}$ \\
\hline other & 229,470 & $20.19^{b, x}$ & 19,626 & $7.61^{c, x}$ & 22,881 & $2.25^{\mathrm{d}, \mathrm{x}}$ & 41,048 & $39.30^{a, w}$ \\
\hline
\end{tabular}

$\mathrm{a}-\overline{\mathrm{d}}$ percentages in the same row with different superscripts differ $(p<0.01){ }^{\mathrm{v}-\mathrm{z}}$ percentages in the same column with different superscripts differ $(p<0.01)$.

The results show that chronic findings predominated in all categories of cattle. The largest number of chronic findings was recorded in cows, in which 1,976,472 findings of a chronic character were made $(173.87 \%)$, which means that, on average, one or two findings were recorded on each cow slaughtered. 
A large number of chronic findings was also detected in calves (91.21\%). The lowest number of chronic findings of all the categories was recorded in bulls $(40.80 \%)$, in which the smallest number of acute findings was also made (3.72\%). The largest number of acute findings was made in calves $(30.60 \%)$ and cows $(29.93 \%)$. The results also show that the category of cattle with the most parasitic findings were heifers $(2.06 \%)$. The fewest parasitic findings were diagnosed in calves $(0.23 \%)$. Differences between the frequency of individual types of findings (acute, chronic, traumatic, parasitic and other) found in the individual categories of cattle were statistically highly significant $(p<0.01)$. All the categories of cattle also differed $(p<0.01)$ in the frequency of individual types of finding.

The trend in the number of intravital pathological findings in individual categories of cattle during the monitored period is given in Figure 1.

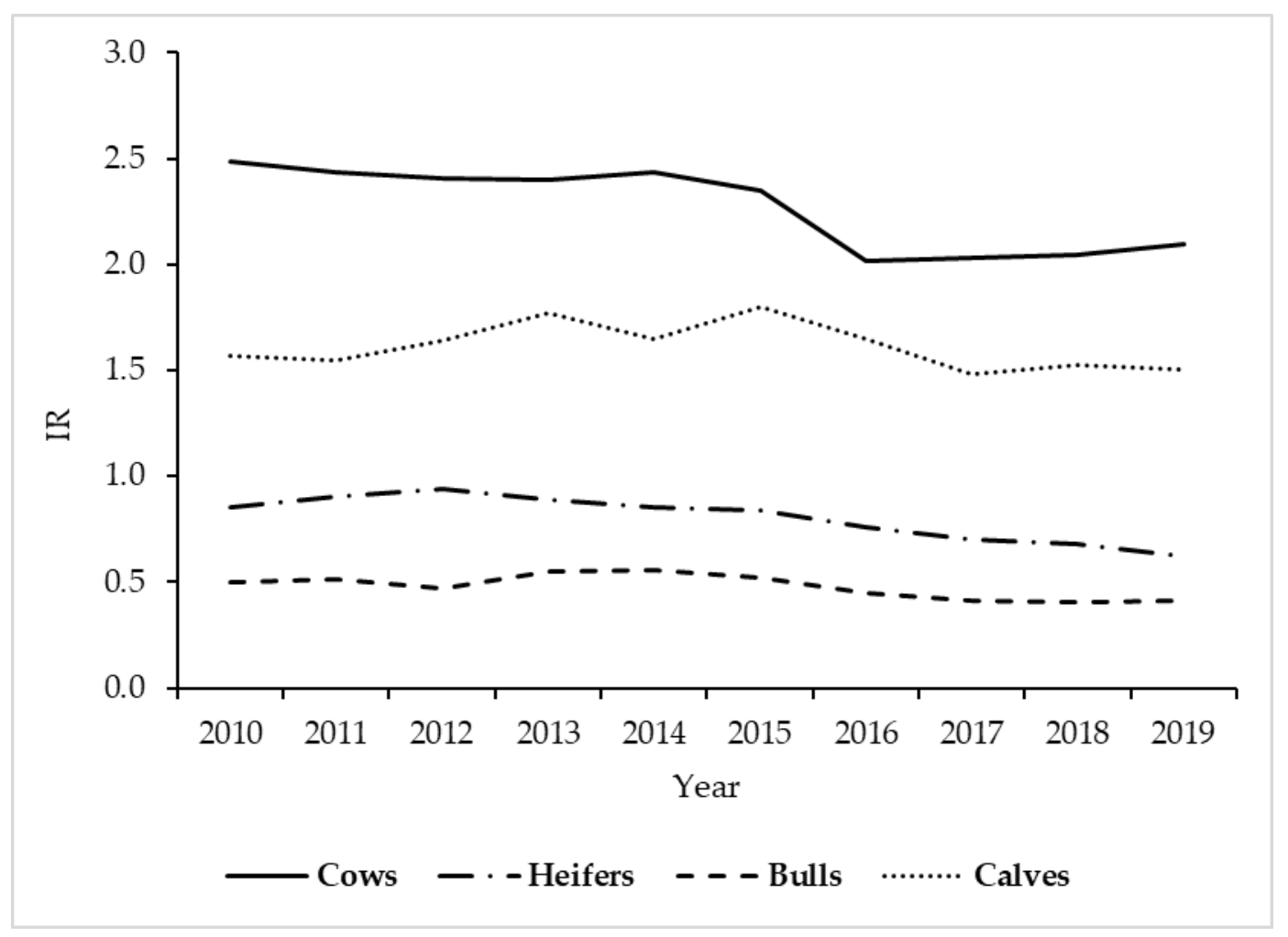

Figure 1. The trend in the number of intravital pathological findings in individual categories of cattle during the monitored period. IR = index of ratio of number of intravital pathological findings to number of slaughtered animals.

In the period from 2010 to 2019, we found a falling trend in heifers in terms of the ratio between intravital findings and the number of animals slaughtered $(\mathrm{rSp}=-0.915, p<0.01)$. A falling trend was also demonstrated in cows (rSp $=-0.806, p<0.01)$ and bulls ( $\mathrm{rSp}=-0.636, p<0.05)$. No falling trend in the number of intravital findings during the monitored period was found in calves $(\mathrm{rSp}=-0.382$, $p>0.05)$.

\section{Discussion}

In recent years, animal welfare, in addition to health, has been considered an important factor affecting the quality of animal products [24]. There is a connection between the protection of animals, the condition of animals before slaughter and the quality of meat from these animals. Kozak et al. [25] also pointed to the fact that the treatment of animals on farms, during transport and at the abattoir is reflected in meat quality. Assuring a good standard of welfare is not merely important from the viewpoint of animal protection and the ethics of animal treatment, but is also important to the 
attainment of meat of high quality from slaughtered animals. Intravital pathological changes detected during veterinary inspections at abattoirs also testify to the standard of health and welfare in cattle.

The results of this study show substantial differences in the number of findings between categories of cattle, testifying to the different state of health of slaughtered cattle. The category of cattle with the most frequently recorded intravital findings (index 2.271) were cows, while the smallest number of intravital findings was seen in bulls (index 0.479). From the viewpoint of the total number of intravital pathological changes, thus the worst state of health is seen in cows, and the best in bulls. Kozak et al. [13] came to the same conclusion. The large number of pathological findings in cows is the result of several years of intensive exploitation which has an impact on their state of health. The great demands on production resulting from the management of dairy farms are manifested in the state of animal health in cows of dairy breeds. Cows are usually culled from the herd at the moment at which their production becomes inadequate or when they show only low reproductive indicators. They are susceptible to production diseases that are not financially viable to treat in the long term. Such animals are therefore discarded from the herd, as is confirmed by the results of the study by Shabalina et al. [26] into the effect of the occurrence of characteristic diseases on the length of the productive period in cows. According to their study, the most frequent reasons for culling cows from dairy farms were mammary gland diseases, infertility and hoof diseases. Among the main reasons for culling, Armengol and Fraile [27] mentioned falling production and low reproductive indicators, which are the result of the overall impairment of the organism and are manifested in typical findings on the carcass.

The number of pathological findings recorded in calves was also high, with an index of 1.618 being found for the ratio of intravital findings to the number of calves slaughtered. According to Radostits et al. [28], a large number of health problems may occur in calves. They mentioned findings associated with diseases of the respiratory and gastrointestinal tracts as the most frequent. Svensson et al. [29] confirmed this, and emphasized the fact that pneumonia and enteritis are the main causes of death in this category of cattle. The large number of total intravital findings in calves is caused by the occurrence of these diseases. If treatment does not begin in time, the calves' health fails, they do not thrive and they become emaciated, which may be reason for their being discarded from the herd and taken to the slaughterhouse.

A lower overall number of intravital findings (index 0.800) was recorded in heifers than in cows or calves. Heifers are generally discarded from the herd as a result of previous diseases at an earlier age. It is not expedient for the farmer to treat these diseases, and the heifers are taken to the slaughterhouse for economic reasons. Prevention in the case of respiratory diseases is often limited merely to the use of vaccines and antibiotics, which may not be sufficient [30]. According to Broom [31], antibiotic treatment of calves with respiratory diseases does not always lead to complete recovery, unless treatment begins in good time, and the disease may become chronic. The grown calves and subsequently heifers do not thrive and are frequently entirely infertile or have reproductive defects, which is a reason for their culling [32]. From the viewpoint of the overall number of intravital findings, the best standard of health was seen in bulls, which may be the result of husbandry and the low age at which bulls intended for fattening are slaughtered. Fattening cattle are usually slaughtered at 15 to 28 months of age [33].

The number of pathological findings was also assessed from the viewpoint of the character of any damage. The results show that chronic findings predominated in all categories of cattle. Chronic changes on the carcasses of slaughtered animals point to the fact that these changes occurred on farms. Their occurrence points to diseases suffered that were not treated in time or not treated at all. The findings point to the chronic progression of diseases. The category of cattle with the greatest frequency of chronic findings was cows $(173.87 \%)$. The results show that one or two findings were detected on each slaughtered cow, i.e., the frequency of chronic findings recorded in cows was greater than in any other category of cattle. Dairy cows in particular are the most exploited category of cattle from the viewpoint of the intensity of production. The organism is not capable of handling such great demands on milk production long-term, and production diseases develop [34]. Production diseases may lead to the gradual failure of the metabolism and are manifested in a number of organ systems. 
These diseases reflect the animal's living conditions and may also be an indicator of poor welfare on the given farm. Mammary gland diseases, low fertility, reduced lactation and diseases of the hoof are thus reason for culling on a number of farms [35]. A number of chronic findings may then be made in various parts of the carcass at the abattoir in connection with these reasons, which accounts for the large number of chronic findings which exceed the number of slaughtered animals in this category. The question remains as to what degree it is possible to reduce the impacts of the great demands of production and reproduction management on their health and welfare. The monitoring of good living conditions is particularly important for cows on dairy farms, where the standard of welfare may be markedly deteriorated as a consequence of intensive farming conditions and the incidence of production diseases. Perceptions of good living conditions for animals may vary considerably among farmers.

A large number of chronic findings were also made in calves (91.21\%), in which diseases, and particularly diseases of the respiratory tract, have a tendency to become chronic. Diseases of the respiratory and gastrointestinal tracts are most common in calves in the first month of life [36]. Tegtmeier et al. [37], who studied the connection between agents of respiratory infections and pathological findings on the lungs in calves in Denmark, confirmed the chronic origin of these findings. They reported purulent, fibrinous and necrotic bronchopneumonia to be a common finding. Of all the categories, the smallest number of chronic findings was recorded in bulls $(40.80 \%)$, in which the lowest number of findings of an acute character was also made (3.72\%). The most acute findings were seen in calves $(30.60 \%)$ and cows $(29.93 \%)$, which is associated with the occurrence of diseases affecting the animals immediately before slaughter, either during transport or at the farm before transport. Transportation is an important factor in the development of respiratory diseases [38]. Calves with "shipping fever" after transport are at greatest risk.

Parasitic findings were detected at only low frequencies in all categories of cattle. The fact that a number of parasites are visible only under the microscope must, however, be taken into consideration during the evaluation of these findings. The low frequency of parasitic findings at abattoirs may be the result of the limited sensitivity of macroscopic veterinary inspections at abattoirs [39]. The occurrence of parasites such as cysticercosis in cattle may be strongly underestimated for this reason throughout the entire European Union [17]. Cabaret et al. [23] further pointed to the fact that veterinary inspections may be performed with differing levels of sensitivity in various countries, in spite of the same demands made on all EU countries by the European legislation. The category of cattle most affected by parasitic findings in our study was heifers $(2.06 \%)$, while the lowest number of parasitic findings was diagnosed in calves $(0.23 \%)$. Calves were also the only category of cattle in which a falling trend in the number of parasitic findings ( $\mathrm{rSp}=-0.879, p<0.01)$ was found during the monitored period. The low prevalence of parasitic findings in calves may be the result of the limited possibilities of detection of certain groups of parasites during veterinary inspection. Parasites that cause diarrhoeal diseases often appear in calves after birth and during the first weeks of life. Proving these by regular veterinary inspection is impossible, as they are mostly protozoa that cannot be confirmed by macroscopic findings [40].

The only category of cattle in which a rising trend in the number of parasitic findings could be seen during the monitored period was cows $(\mathrm{rSp}=0.685, p=0.03)$. No rising trend was shown in the number of parasitic findings during the monitored period in bulls ( $\mathrm{rSp}=0.188, p>0.05)$ or heifers $(\mathrm{rSp}=0.200, p>0.05)$. A rising trend in adult cattle may be the result of the expansion in the rearing of both beef and dairy breeds on pasture. In beef cattle in particular, when the animals are reared on pasture as calves, a heavy infestation of the pastures with parasites can lead to a substantial parasitic infection that can be demonstrated at the abattoir by the presence of parasitic findings. Older animals are often a source of infection for calves on pasture. A high prevalence of gastrointestinal parasites may be the result of an unsuitable or entirely lacking system of inspection for the occurrence of parasites on the pastures and in animals [41].

A low number of findings of a traumatic origin was recorded in all categories of cattle. Traumatic findings included fractures, contusions, bruising and swelling. The occurrence of these 
changes is caused by inconsiderate treatment or fighting between animals [42]. Unsuitable husbandry or hygiene may also be causes. According to Simova et al. [8], young animals in particular are more sensitive to trauma during transport. In connection with transport, the authors emphasized the importance of favoring the farmer or the carrier transporting the animals to the nearest abattoir. Furthermore, a shorter distance may reduce the risk of injury and limit the impact of transport itself on the welfare of the slaughtered animals.

The highest incidence of traumatic changes was found in cows (1.71\%). The greater frequency of traumatic findings in cows may be due to the use of unsuitable housing systems, for example dirty unconsolidated floors leading to the milking parlour may cause animals to slip and sustain fractures. The incidence of pathological changes of a traumatic origin was lowest in bulls $(0.28 \%)$. Similarly, Bethancourt-Garcia et al. [43] found a lower incidence of contusions in bulls (17.2\%) than in cows (38.6\%). Strappini et al. [44], who studied the occurrence of contusions in cows in Chile, reached the same conclusion. The results of their study confirmed the fact that contusions are more frequent in cows than in bulls after transport. The physique and the robustness of the body is also an important factor influencing the occurrence of traumatic findings. A strong adult bull is more resilient to injuries of varying etiology in comparison with other categories of cattle [45]. The low number of traumatic findings recorded in this study can be considered a positive finding indicating the improving standard of welfare during transportation and on cattle farms.

The group of other findings also represented an important group of findings from the viewpoint of the frequency of occurrence. The category of cattle with the greatest frequency of other findings was calves $(39.30 \%)$. Other findings included infectious and other changes to the skin, tumours on the skin, icterus on the liver, total changes, pathological pregnancy and genital developmental defects, and other intravital findings that are not specified in greater detail and that accounted for $44.72 \%$ of all other findings in calves. This category is not defined in detail and may be a cause of distortion of the overall assessment of the state of health during the assessment of lesions at the abattoir. The lack of a clear definition of types of findings may lead to a different approach in the scoring of lesions by official veterinary inspectors. A different approach to the assessment of findings was also mentioned by Wanda et al. [46] as a possible reason for the variability of findings between individual states.

Evaluation of the trend in the overall number of intravital pathological findings in individual categories of cattle shows that a demonstrable reduction in the ratio of intravital findings to the number of slaughtered animals occurred in heifers, cows and bulls in the monitored period. The falling trend in the incidence of intravital pathological changes can be considered a positive finding pointing to an improving standard of health and welfare among these categories of bovine animals. It must, however, be mentioned that the frequency of the overall number of intravital pathological findings in cows is still far higher than it is in bulls or heifers. If we are talking about a marked improvement in the state of health, then we are talking primarily about bulls and heifers. Heifers represent the next generation of the production herd for farmers. A good standard of health and welfare in this category is essential to successful farming. In calves, the number of intravital findings during the monitored period did not change significantly and indicates a long-term poor level of their health. Calves should also not be neglected in terms of their importance to shaping the future generation of the herd and a long-term unfavourable standard of health reflects the approach of farmers to the treatment of diseases.

\section{Conclusions}

The standard of health and the welfare of slaughtered cattle have an impact on the findings made during veterinary inspections, and differ between cows, heifers, bulls and calves, dependent on the frequency and scale of the detected changes. The current conditions of intensive farming can assure the sustainable health of animals, good yield and the quality of animal products. The standard of welfare is the standard of good living conditions for the animals from which farmers themselves profit. Further improvements in living conditions need not lead to improved production results, though they 
may benefit the animals themselves. Further improvements of this kind, however, are not generally implemented on farms, as they are economically disadvantageous.

Author Contributions: Conceptualization, V.V. and Z.S.; methodology, V.V. and E.V.; validation, V.V.; formal analysis, V.V., A.P. and E.V.; Investigation, V.V. and Z.S.; Writing-original draft preparation, M.K., V.V.; writing-review and editing, M.K., E.V., and A.P.; visualization, M.K.; supervision, V.V.; Funding acquisition, V.V. All authors have read and agreed to the published version of the manuscript.

Funding: This study was supported by ITA VFU Brno (Project No. FVHE/Vecerek/ITA2019).

Conflicts of Interest: The authors declare no conflict of interest.

\section{References}

1. Stark, K.; Alonso, S.; Dadios, N.; Dupuy, C.; Ellerbroek, L.; Georgiev, M.; Hardstaff, J.; Huneau-Salaün, A.; Laugier, C.; Mateus, A.; et al. Strengths and weaknesses of meat inspection as a contribution to animal health and welfare surveillance. Food Control 2014, 39, 154-162. [CrossRef]

2. Vecerek, V.; Malena, M.; Voslarova, E.; Bedanova, I. Mortality in Dairy Cows Transported to Slaughter as Affected by Travel Distance and Seasonality. Acta Veter. Brno 2006, 75, 449-454. [CrossRef]

3. Vecerkova, L.; Voslarova, E.; Vecerek, V. Comparison of the welfare of laying hens, broiler chickens and turkeys in terms of bird health as surveyed during inspection in slaughterhouses. Acta Veter. Brno 2019, 88, 243-248. [CrossRef]

4. Ceccarelli, M.; Leprini, E.; Sechi, P.; Iulietto, M.F.; Grispoldi, L.; Goretti, E.; Cenci-Goga, B.T. Analysis of the causes of the seizure and destruction of carcasses and organs in a slaughterhouse in central Italy in the 2010-2016 period. Ital. J. Food Saf. 2018, 7, 40-44. [CrossRef]

5. Fries, R. Meat Inspection Findings-A Mirror of Animal Health. Tierarztl. Umsch. 1994, 49, 642-647.

6. Webster, J. Animal Welfare: Freedoms, Dominions and "A Life Worth Living". Animal 2016, 6, 35. [CrossRef]

7. Troeger, K. Animal welfare in husbandry, transport and slaughter of farm animals. Fleischwirtschaft 1996, $76,1222-1227$.

8. Simova, V.; Vecerek, V.; Passantino, A.; Voslarova, E. Pre-transport factors affecting the welfare of cattle during road transport for slaughter-A review. Acta Veter. Brno 2016, 85, 303-318. [CrossRef]

9. Nicholson, J.D.; Nicholson, K.L.; Frenzel, L.L.; Maddock, R.J.; Delmore, R.J.; Lawrence, T.E.; Henning, W.R.; Pringle, T.D.; Johnson, D.D.; Paschal, J.C.; et al. Survey of transportation procedures, management practices, and health assessment related to quality, quantity, and value for market beef and dairy cows and bulls1. J. Anim. Sci. 2013, 91, 5026-5036. [CrossRef]

10. Köfer, J.; Kutschera, G.; Fuchs, F. Tiergesundheitsmonitoring durch Organbefundung am Schlachthof. Fleischwirtschaft 2001, 10, 107-111.

11. Lis, H. Results of veterinary inspection of slaughter animals and meat in Poland in 2003. Med. Weter. 2005, 61, 1160-1161.

12. Dupuy, C.; Morignat, E.; Maugey, X.; Vinard, J.-L.; Hendrikx, P.; Ducrot, C.; Calavas, D.; Gay, E. Defining syndromes using cattle meat inspection data for syndromic surveillance purposes: A statistical approach with the 2005-2010 data from ten French slaughterhouses. BMC Veter. Res. 2013, 9, 88. [CrossRef] [PubMed]

13. Kozak, A.; Vecerek, V.; Steinhauserova, I.; Chloupek, P.; Pistekova, V. Results of slaughterhouse carcass classification (capable for human consumption, capable for processing and condemned) in selected species of food animals. Veter. Med. 2002, 47, 26-31. [CrossRef]

14. Vecerek, V.; Kozak, A.; Malena, M.; Tremlova, B.; Chloupek, P. Veterinary meat inspection of bovine carcasses in the Czech Republic during the period of 1995-2002. Veter. Med. 2003, 48, 183-189. [CrossRef]

15. Lis, H. Results of veterinary inspection of slaughtered animals and meat in Poland in 2000. Med. Weter. 2002, 58, 267-269.

16. Lis, H. An evaluation of veterinary inspection of slaughtered animals and meat in Poland between 1987-1997. Med. Weter. 1999, 55, 243-246.

17. Dorny, P.; Praet, N. Taenia saginata in Europe. Veter. Parasitol. 2007, 149, 22-24. [CrossRef]

18. Salimi-Bejestani, M.; McGarry, J.; Felstead, S.; Ortiz, P.; Akca, A.; Williams, D. Development of an antibody-detection ELISA for Fasciola hepatica and its evaluation against a commercially available test. Res. Veter. Sci. 2005, 78, 177-181. [CrossRef] 
19. Cassini, R.; Mulatti, P.; Zanardello, C.; Simonato, G.; Signorini, M.; Cazzin, S.; Tambalo, P.G.; Cobianchi, M.; Pietrobelli, M.; Capelli, G. Retrospective and spatial analysis tools for integrated surveillance of cystic echinococcosis and bovine cysticercosis in hypo-endemic areas. Geospat. Health 2014, 8, 509-515. [CrossRef]

20. Mage, C.; Bourgne, H.; Toullieu, J.-M.; Rondelaud, D.; Dreyfuss, G. Fasciola hepatica and Paramphistomum daubneyi: Changes in prevalences of natural infections in cattle and in Lymnaea truncatula from central France over the past 12 years. Veter. Res. 2002, 33, 439-447. [CrossRef]

21. Dupuy, C.; Morlot, C.; Demont, P.; Ducrot, C.; Calavas, D.; Callait-Cardinal, M.-P.; Gay, E. Construction of standardized surveillance indicators for bovine cysticercosis. Prev. Veter. Med. 2014, 115, 288-292. [CrossRef] [PubMed]

22. Dupuy, C.; Morlot, C.; Gilot-Fromont, E.; Mas, M.; Grandmontagne, C.; Gilli-Dunoyer, P.; Gay, E.; Callait-Cardinal, M.-P. Prevalence of Taenia saginata cysticercosis in French cattle in 2010. Veter. Parasitol. 2014, 203, 65-72. [CrossRef] [PubMed]

23. Cabaret, J.; Bouilhol, M.; Mage, C. Managing helminths of ruminants in organic farming. Veter. Res. 2002, 33, 625-640. [CrossRef] [PubMed]

24. Buller, H.; Cesar, C. Eating Well, Eating Fare: Farm Animal Welfare in France. Int. J. Sociol. Agric. Food 2007, $15,45-58$.

25. Kozak, A.; Vecerek, V.; Chloupek, P.; Tremlova, B.; Malena, M. Veterinary meat inspection of pig carcasses in the Czech Republic during the period of 1995-2002. Veter. Med. 2003, 48, 207-214. [CrossRef]

26. Shabalina, T.; Yin, T.; König, S. Influence of common health disorders on the length of productive life and stayability in German Holstein cows. J. Dairy Sci. 2019, 103, 583-596. [CrossRef] [PubMed]

27. Armengol, R.; Fraile, L.J. Descriptive study for culling and mortality in five high-producing Spanish dairy cattle farms (2006-2016). Acta Veter. Scand. 2018, 60, 1-11. [CrossRef]

28. Radostits, M.O.; Gay, C.C.; Hinchcliff, K.W.; Constable, P.D. Veterinary Medicine: A Textbook of the Diseases of Cattle, Horses, Sheep, Pigs and Goats, 10th ed.; Saunders Ltd.: New York, NY, USA, 2007.

29. Svensson, C.; Linder, A.; Olsson, S.-O. Mortality in Swedish Dairy Calves and Replacement Heifers. J. Dairy Sci. 2006, 89, 4769-4777. [CrossRef]

30. Penny, C. The control of bovine respiratory disease (BRD)-Are we making progress? BCVA Cattle Pract. 2015, 25, 314-319.

31. Broom, D.M. Needs and Welfare of Housed Calves. In Proceedings of the New Trends in Veal Calf Production, Wageningen, The Netherlands, 14-16 March 1990; EAAP Publications: Wageningen, The Netherlands, 1991; pp. 23-31.

32. Pritchard, G.C.; Forbes, A.B.; Williams, D.J.L.; Salimi-Bejestani, M.R.; Daniel, R.G. Emergence of fasciolosis in cattle in East Anglia. Veter. Rec. 2005, 157, 578-582. [CrossRef]

33. Drouillard, J.S. Current situation and future trends for beef production in the United States of America-A review. Asian-Australas. J. Anim. Sci. 2018, 31, 1007-1016. [CrossRef] [PubMed]

34. Mulligan, F.; O'Grady, L.; Rice, D.; Doherty, M. Production diseases of the transition cow: Milk fever and subclinical hypocalcaemia. Irish Vet. J. 2006, 59, 7.

35. Ahlman, T.; Berglund, B.; Rydhmer, L.; Strandberg, E. Culling reasons in organic and conventional dairy herds and genotype by environment interaction for longevity. J. Dairy Sci. 2011, 94, 1568-1575. [CrossRef]

36. Bojkovski, J.A.; Milanov, D.S.; Savić, S.; Vasić, A.; Zdravkovic, N.; Rogozarski, D.; Prokic, N.; Korica, S. Respiratory Diseases of Calves on Dairy Cow Farm. Bull. Univ. Agric. Sci. Veter. Med. Cluj-Napoca. Veter. Med. 2014, 71, 313-320. [CrossRef]

37. Tegtmeier, C.; Uttenthal, A.; Friis, N.F.; Jensen, N.E.; Jensen, H.E. Pathological and Microbiological Studies on Pneumonic Lungs from Danish Calves. Zent. Veter. Reihe B. J. Veter. Med. Ser. B 2002, 46, 693-700. [CrossRef]

38. Taylor, J.D.; Fulton, R.W.; Lehenbauer, T.W.; Step, D.L.; Confer, A.W. The epidemiology of bovine respiratory disease: What is the evidence for predisposing factors? Can. Vet. J. 2010, 51, 1095-1102. [PubMed]

39. Dorny, P.; Vercammen, F.; Brandt, J.; Vansteenkiste, W.; Berkvens, D.; Geerts, S. Sero-epidemiological study of Taenia saginata cysticercosis in Belgian cattle. Veter. Parasitol. 2000, 88, 43-49. [CrossRef]

40. Göz, Y.; Altuğ, N.; Yüksek, N.; Özkan, C. Parasites detected in neonatal and young calves with diarrhoes. Bull. Vet. Inst. Pulawy 2006, 50, 345-348.

41. Kobak, P.; Pilarczyk, B. Prevalence of Gastrointestinal Parasites of Water Buffaloes Raised in the Notecka Forest Region (Poland). Bull. Veter. Inst. Pulawy 2012, 56, 33-36. [CrossRef] 
42. Costa, L.N.; Fiego, D.P.L.; Tassone, F.; Russo, V. The Relationship Between Carcass Bruising in Bulls and Behaviour Observed During Pre-slaughter Phases. Veter. Res. Commun. 2006, 30, 379-381. [CrossRef]

43. Bethancourt-Garcia, J.A.; Vaz, R.; Vaz, F.N.; Silva, W.B.; Pascoal, L.L.; Mendonça, F.S.; Da Vara, C.C.; Nuñez, A.J.C.; Restle, J. Pre-slaughter factors affecting the incidence of severe bruising in cattle carcasses. Livest. Sci. 2019, 222, 41-48. [CrossRef]

44. Strappini, A.C.; Metz, J.H.M.; Gallo, C.B.; Kemp, B. Origin and assessment of bruises in beef cattle at slaughter. Animal 2009, 3, 728-736. [CrossRef] [PubMed]

45. Schwartzkopf-Genswein, K.S.; Faucitano, L.; Dadgar, S.; Shand, P.; González, L.; Crowe, T. Road transport of cattle, swine and poultry in North America and its impact on animal welfare, carcass and meat quality: A review. Meat Sci. 2012, 92, 227-243. [CrossRef] [PubMed]

46. Wanda, S.; Schleicher, C.K.; Scheriau, S.; Köfer, J. Austrian Model Approach to Assess Quality of Post-Mortem Feedback-Information Systems in Pigs. In Proceedings of the 10th International Conference on the Epidemiology and Control of Biological, Chemical and Physical Hazards in Pigs and Pork, Lisbon, Portugal, 9-12 September 2013; The Iowa State University Digital Press: Iowa, IA, USA, 2013; pp. 207-210.

Publisher's Note: MDPI stays neutral with regard to jurisdictional claims in published maps and institutional affiliations.

(C) 2020 by the authors. Licensee MDPI, Basel, Switzerland. This article is an open access article distributed under the terms and conditions of the Creative Commons Attribution (CC BY) license (http://creativecommons.org/licenses/by/4.0/). 